\title{
O uso do comércio eletrônico pelos professores, funcionários e alunos da Faculdade de Tecnologia Senac de São Miguel do Oeste
}

\author{
Cassiane Regina Hanauer ${ }^{1}$ \\ Josiane Romancini ${ }^{2}$
}

\section{RESUMO}

O comércio eletrônico é uma ferramenta da internet, utilizada para fazer transações comerciais, principalmente por empresa-consumidor. Esta pesquisa procurou mostrar como é feito o uso do comércio eletrônico, o perfil de seus consumidores, a comunicação destes com a empresa, as vantagens e desvantagens desta ferramenta de compra. Os métodos de pesquisa utilizados foram pesquisa exploratória, para o conhecimento da problematização do estudo; descritiva, pois foram utilizados, como instrumento de pesquisa, questionários, e pesquisa bibliográfica, para o conhecimento e aprofundamento do tema comércio eletrônico. Com a pesquisa, pôde ser observado que há um interesse das pessoas pela utilização do comércio eletrônico; porém, ainda existe uma falta de confiança para a utilização desta ferramenta de compra. Mesmo aquelas pessoas que não fazem a utilização do comércio eletrônico, acreditam que ele tem vantagens, como preços mais acessíveis do que no comércio local e, também, em virtude da comodidade em estar fazendo compras sem precisar sair de casa. Já como desvantagens, citam-se a falta de contato com o produto e a falta de segurança, pois os entrevistados acreditam que o número do cartão de crédito pode ser utilizado por outras pessoas. Constatamos igualmente que há ainda muita resistência na utilização do comércio eletrônico; entretanto, para muitos, não é visto apenas como uma evolução da tecnologia, mas como uma vantagem tanto da empresa que trabalha com tal ferramenta, como do consumidor que pode acessar vários sites, verificar os produtos, fazer cotações de preço para, posteriormente, fazer suas compras.

Palavras-chave: Comércio Eletrônico. Consumidor. Segurança.

\section{INTRODUÇÃO}

O comércio eletrônico é mais uma inovação da tecnologia, que permite a troca de produtos e/ou serviços por meio da internet, sendo mais uma ferramenta do meio eletrônico. 
A pesquisa teve como objetivo verificar se os professores, funcionários e alunos da Faculdade de Tecnologia Senac, de São Miguel do Oeste - Santa Catarina -, fazem uso do comércio eletrônico. Identificamos o perfil desses consumidores; averiguamos se eles acham seguro comprar pela internet, que tipo de produtos essas pessoas adquirem e se compram efetivamente ou apenas fazem pesquisa na internet sobre os produtos que pretendem comprar.

Foram aplicados questionários com todos os professores, funcionários e alunos da Faculdade de Tecnologia Senac, de São Miguel do Oeste - Santa Catarina, a qual trabalha com um curso tecnólogo de Gestão Comercial, cursos livres e técnicos.

Com a aplicação dos questionários, pôde-se conhecer o ponto de vista dos consumidores para com o comércio eletrônico, além de conhecer o perfil dos consumidores e entender o que o comércio eletrônico tem como vantagens e desvantagens.

Pesquisamos também como é a relação do consumidor e da empresa que trabalha com o comércio eletrônico e qual é o ponto de vista e a aceitação dos professores, funcionários e alunos da Faculdade de Tecnologia Senac, de São Miguel do Oeste.

\section{COMÉRCIOELETRÔNICO}

O comércio eletrônico identifica o uso intensivo de Tecnologia da Informação, segundo Segev (1995 apud DINIZ, 1999), na mediação das relações entre consumidores e fornecedores. Para melhor compreensão das vantagens e riscos do comércio eletrônico, no entanto, é útil a sua divisão em dois blocos principais.

0 mesmo autor ressalta que o primeiro bloco indica as atividades relativas a transações entre empresas que compram e vendem produtos entre si. Esse grupo se caracteriza por um número relativamente baixo de transações de alto valor financeiro. 0 segundo bloco, das transações entre empresas e consumidores finais, caracteriza-se por alto volume relativo de transações com baixo valor financeiro envolvido em cada uma delas.

0 comércio eletrônico é uma ferramenta da internet, utilizada para transações comerciais por empresas entre em si, e entre empresas e consumidor final.

Bransky (1999 apud TOLEDO; CAIGAWA; ROCHA, 2006) define o comércio eletrônico como a ação de compartilhar informações, manutenção de relacionamentos e condução de transações de negócios por meio de rede de telecomunicações dentro e fora das empresas. Assim, o comércio eletrônico é a maneira pela qual vendas e compras são geradas, on-line. Ainda segundo o mesmo autor, a internet é a ferramenta de inegável importância no comércio eletrônico, uma vez que possui uma tecnologia de fácil entendimento e possui o domínio público: qualquer pessoa, em qualquer lugar, pode acessá-la, bastando para isso um computador e uma linha telefônica. Essa facilidade passou a orientar as empresas quanto à venda ao cliente final, sem a necessidade de investimentos vultosos, criando grande interesse em números cada vez maior de setores econômicos.

Esse meio permite que se realize qualquer compra, 24 horas por dia, 7 dias por semana e 365 dias por ano; além disso, oferece vantagem de comodidade, sem a necessidade de sair de casa, enfrentar trânsito e muitas vezes adquirir um produto por um menor valor do que no comércio local.

Apesar de a web ter simplificado imensamente a utilização da internet, ela ainda é essencialmente uma rede de computadores. Os computadores ainda não são tão simples de se utilizar quanto uma TV ou um telefone, por exemplo.

Esse aspecto é especialmente crítico, se for considerada a multiplicidade de serviços que podem ser implementados para o atendimento on-line de consumidores e que devem ser programados pelos próprios usuários. Deve-se esperar que a velocidade de adesão aos sistemas de comércio eletrônico esteja também atrelada ao nível de complexidade deles.

De acordo com Parasuraman, Zeithaml e Malhotra (1991 apud VIEIRA, 2010, p. 3),

[...] a vantagem deste novo instrumento é a 'especificidade' para o meio eletrônico. Os autores chegaram a três grandes conclusões: (i) a noção de que a qualidade dos serviços vem de uma comparação do desempenho atual do serviço com a expectativa, (ii) os cinco fatores da qualidade da ServQual (confiabilidade, capacidade de resposta, segurança, empatia e responsabilidade) captam o domínio geral da qualidade dos serviços, e (iii) as avaliações dos consumidores sobre a qualidade do serviço são fortemente ligadas ao valor percebido e às intenções comportamentais. 
Depois de estudos realizados para saber da qualidade no ambiente eletrônico, os pesquisadores citados concluíram que há

\author{
Qualidade de eficiência: facilidade e velocidade de acessar o site. \\ Qualidade de disponibilidade do sistema: a funcionalidade correta e técnica do site. \\ Qualidade de preenchimento: a extensão na qual o site promete entregar o pedido de modo correto e \\ eficaz, juntamente com a sua disponibilidade. \\ Qualidade de privacidade: o grau no qual o site demonstra segurança e sigilo nas informações \\ particulares do consumidor. (PARASURAMAN; ZEITHAML; MALHOTRA, 1991 apud VIEIRA, 2010, p. 3).
}

Diante das conclusões dos autores, pode-se perceber que os sites, quando bem trabalhados, podem ter uma ampla qualidade, tornando fácil o acesso a eles, com uma boa funcionalidade, cumprindo com o que prometem e passando segurança ao consumidor.

Porém, nem todas as pessoas veem o comércio eletrônico com essas qualidades. Por isso, a implementação do referido meio não será vista do mesmo modo em todo lugar do mundo, em virtude de culturas diferentes e por haver países com diferentes hábitos de consumo.

Outras barreiras, como a língua e peculiaridades culturais, são mais difíceis de serem avaliadas, mas também podem constituir obstáculos para a ampla disseminação de transações comerciais on-line em nível global, embora não invalidem a utilização do comércio eletrônico em regiões geograficamente delimitadas. Isso significa que não basta alguém ter acesso aos recursos da internet para fazer aquisições em qualquer lugar do planeta, não obstante isso seja virtualmente possível. Assim, a acomodação de diferenças culturais, fenômeno intrínseco às atividades de comercialização global on-line, deve ser levada em conta no desenvolvimento dos sistemas do comércio eletrônico (DINIZ, 1999).

Steinfield, Kraut e Plummer (1995 apud DINIZ, 1999) ressaltam que não é só por fatores culturais e pelo perfil do consumidor que os processos de compra se distinguem. Há que se considerar que a adoção dos sistemas de comércio eletrônico estará associada ao tipo de produto fornecido.

Pode ser considerada uma desvantagem a transmissão digital on-line das informações contidas nesse tipo de produto, apesar de ser viável tecnicamente e de estar sendo acreditada por muitos como uma possibilidade mais interessante do comércio eletrônico, depende de uma aceitação ampla de massa de consumidores que, mesmo tendo a possibilidade de selecionar os produtos eletronicamente, tem o desejo de possuir fisicamente 0 objeto de sua compra (DINIZ, 1999).

A falta de contato com o produto, a confiabilidade, a chegada do produto que se compra em bom estado físico; que a cor, por exemplo, será a mesma escolhida no site, são alguns aspectos que devem ser considerados.

Outro fator importante é a confiança sobre os dados pessoais. Pela possibilidade de invasão de pessoas, querendo roubar informações pessoais, muitos se recusam a realizar compras pelo comércio eletrônico. Apesar dessa percepção, da existência de roubos de dados pessoais na internet poder ser considerada exagerada, Kline (1995 apud DINIZ, 1999) afirma que ela existe e deve ser levada em conta, para que o uso dos sistemas de comércio eletrônico possa ser expandido. Alem disso, a facilidade de se criarem empresas em qualquer lugar do mundo todo implica o risco de um consumidor transacionar com uma empresa virtual, que desaparece assim que recolhe o seu dinheiro.

E por todos os motivos já descritos, Diniz (1999, p. 78, grifo do autor) ressalta que

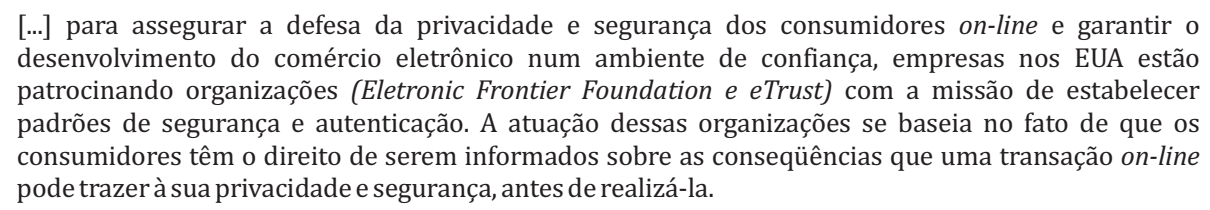

Portanto, há um grande beneficio para as empresas virtuais se elas fizerem uso de ambientes de segurança, pois podem ser reconhecidas como seguras para a realização de compras e, assim, os consumidores poderão efetuar as suas compras sem o receio de o número do seu cartão de crédito e outras informações confidenciais serem utilizadas por outras pessoas.

Todavia, para as empresas conseguirem vender e atingir suas metas, é necessário criarem-se estratégias para a venda. Segundo Laudon e Laudon (2004 apud TOLEDO; CAIGAWA; ROCHA, 2006, p. 123), “a Internet é 
uma ferramenta poderosa para vendas e marketing, pois fornece capacidade para a personalização e interação com clientes que não podem ser encontradas em outros canais". Empresas podem manter diálogos continuados com clientes, usando e-mail, bate-papo e grupos de discussão eletrônica, para solidificar seus relacionamentos com eles.

Dentro do comércio eletrônico, ao mesmo tempo, as empresas podem fazer uso do Composto de Marketing (Produto/Serviço; Preço; Praça; Promoção). Kotler (2002 apud TOLEDO; CAIGAWA; ROCHA, 2006) considera o Composto de Marketing como um conjunto de ferramentas que a empresa utiliza para perseguir seus objetivos de venda no mercado alvo.

Nesse sentido, uma das vantagens da internet para decisões de Produto, por exemplo, é permitir simulação de cores, para uma mesa de centro, por exemplo, é possível optar pela cor da mesa que mais combina com a casa do cliente. Assim sendo, Kosiur (1997 apud TOLEDO; CAIGAWA; ROCHA, 2006) acrescenta que a tecnologia da internet também consente que os catálogos eletrônicos sejam atualizados de maneira dinâmica e rapidamente. As empresas devem fazer uso desses catálogos para não perderem seu espaço no mercado.

Exceto pelos novos produtos em formato digital, como música, livros, softwares, e alguns serviços, a abordagem às decisões relacionadas aos produtos não necessariamente mudou em relação às práticas tradicionais; acrescentaram-se, talvez, alguns aspectos, como, por exemplo, segurança e privacidade das informações fornecidas, rapidez em download, que nem sempre depende apenas do web site (TOLEDO; CAIGAWA; ROCHA, 2006)

No entanto, uma vez que o produto comercializado pela internet não pode ser tocado nem provado no ato da compra, que as cores visualizadas no monitor do computador provavelmente não são exatamente iguais às originais e que os sistemas de simulação de odores ainda se encontram em seus estágios iniciais, o que mudou com a utilização da Internet como ferramenta comercial de suporte às decisões sobre produtos foi a possibilidade de proporcionar incremento de seus atributos para os clientes, diferenciando-os e tornando a sua seleção uma experiência atrativa e vantajosa (TOLEDO; CAIGAWA; ROCHA, 2006, p.125).

Segundo a primeira versão de 4Ps de McCarthy (1996 apud TOLEDO; CAIGAWA; ROCHA, 2006), a Praça está relacionada a onde, quando e por quem o produto seria comercializado.

Entende-se por Praça, então, todo o caminho que o produto percorre, desde sua matéria-prima até seu consumidor final.

Há empresas que já optaram em trabalhar somente com o comércio eletrônico. A internet proporciona algumas inovações relativamente ao 'P' de Praça. A primeira delas é o boom de desintermediação, em que o fabricante passa a vender diretamente para o consumidor final, seja no caso de um produto simples, como sapato, seja de produtos mais complexos, como seguros de vida ou computadores, por exemplo. 0 processo de desintermediação provoca a revisão de alguns subsistemas do setor varejista e acrescenta novos desafios para o fabricante que decide vender diretamente ao consumidor final (TOLEDO; CAIGAWA; ROCHA, 2006)

O contato direto, no qual o fabricante dá mais atenção direta ao consumidor final, faz com que este se sinta único para a empresa.

Por outro lado, Windham (1999 apud TOLEDO; CAIGAWA; ROCHA, 2006) lembra que a internet criou oportunidades para o surgimento de outros tipos de intermediários. São empresas que oferecem vendas ou serviços de conteúdo, tornando a condução de negócios na Internet mais fácil, identificando oportunidades e preenchendo lacunas criadas por ela.

\footnotetext{
Os benefícios aos clientes incluem assistência na busca e avaliação de produtos e serviços, avaliação de necessidades e busca de produtos adequados, redução de risco e entrega ou distribuição de produtos. Já os benefícios aos produtores dos web sites incluem a criação e disseminação de informações sobre os produtos, criação de consciência sobre o produto, influência na compra dos clientes, fornecimento de informações sobre os clientes, redução da exposição ao risco e redução de custos de distribuição por intermédio de economias de escala de transações (TOLEDO; CAIGAWA; ROCHA, 2006, p. 125).
}

No entanto, alguns segmentos do mercado não podem eliminar completamente os intermediários por meio de web sites. Conforme os gestores de marketing, uma séria limitação presente no sistema de distribuição parece ser a entrega dos produtos ao consumidor final. Um dos problemas é o custo da logística, por meio de entregas rápidas, como os correios. Bonne e Kutz (2001 apud TOLEDO; CAIGAWA; ROCHA, 2006) sugerem que, para que o comércio eletrônico se torne uma poderosa ferramenta de distribuição, deverá haver logística e 
praça física competente, com prazos e condições aceitáveis de entrega. Além disso, uma logística eficaz requer um gerenciamento adequado da cadeia de fornecimento, o que envolve a integração, desde os fornecedores de matérias-primas, passando pelo processo de produção e chegando à movimentação física dos bens produzidos até os clientes.

Não basta ter um produto disponível, com vantagens e que atraiam o consumidor, se não houver uma distribuição adequada e eficaz para tal produto, que cumpra os prazos combinados e que o produto em si esteja em condições adequadas.

Outra estratégia é o preço. Boone e Kurtz (2001 apud TOLEDO; CAIGAWA; ROCHA, 2006) afirmam que as decisões envolvendo preço são decisivas para o alcance dos resultados econômicos e financeiros, para o posicionamento estratégico competitivo da empresa, para a consecução de objetivos relacionados a volume de vendas e a prestígio.

Alguns modelos de precificação são utilizados na internet, assim como na vida real. Turban (2000 apud TOLEDO; CAIGAWA; ROCHA, 2006, p. 10) apresenta os mais utilizados:

\footnotetext{
-Dinâmica: trata-se de um mecanismo que concilia oferta e demanda por meio de uma estrutura de preços.

-Variável: esse recurso objetiva gerar vendas e receitas incrementais, pela variação do processo de um item. Um produto, a título de experimentação, pode ser oferecido com desconto, para então ser vendido ao preço inicialmente determinado, depois de aprovado.
}

Laudon e Laudon (2004 apud TOLEDO; CAIGAWA; ROCHA, 2006, p. 127) lembram que a internet ampliou o poder de barganha do consumidor, ao possibilitar o surgimento de ferramentas:

\footnotetext{
1. Comparação instantânea de preços: consumidor pode verificar o preço do bem que deseja comprar em várias lojas digitais, simultaneamente, e escolher o menos preço disponível.

2. Leilão reverso: essa ferramenta possibilita a realização de leilões pelo valor menos ao contrário do leilão tradicional.

3. Mecanismos 'defina seu preço': o consumidor define o preço que deseja pagar por uma mercadoria ou um serviço, e o web site busca fornecedores que atendam o consumidor.

4. Grupos de compras: consiste na criação de grupos de consumidores interessados na aquisição do mesmo bem e negociam com vários fornecedores, obtendo menores preços.
}

Na vida real, isso já era possível, mas com a comodidade e facilidade no comércio eletrônico, está ganhando cada vez mais espaço.

Boone e Kurtz (2001 apud TOLEDO; CAIGAWA; ROCHA, 2006, p. 127), no entanto, [...] "tendo em vista a existência de mecanismos que facilitam a comparação instantânea de preços, acenam com a tendência de padronização deles, que não serão necessariamente baixos".

Os compradores on-line podem comparar características e preços à vontade, sem serem pressionados por um vendedor, ou restritos aos horários de operação ou a certos limites geográficos (TOLEDO; CAIGAWA; ROCHA, 2006). Dessa maneira, fazem uma negociação mais calma, que lhes permite fazer uma escolha sem a persistência de vendedores.

A última estratégia, mas não menos importante, é quanto à promoção. Segundo Bishop (2000 apud TOLEDO; CAIGAWA; ROCHA, 2006), a promoção por meio da internet é mais racional do que emocional o que implica um processo de persuasão e não apenas de informação, podendo variar, evidentemente, conforme o tipo de produto ou serviço. Ainda, de acordo com o mesmo autor, as ações promocionais têm os seguintes objetivos: fornecer informações para consumidores e outros interessados, aumentar a procura, diferenciar um produto ou serviço, incrementar valor de um produto ou serviço, estabilizar as vendas.

Com o advento da utilização da internet como mídia eletrônica alternativa de propagandas, muitos acham que haveria uma inundação de teclas de promoções nos computadores. Segundo Al Ries (2000 apud TOLEDO; CAIGAWA; ROCHA, 2006, p. 126),

[...] essa projeção para o futuro não se sustentava e por fim não ocorreu. Conforme o autor, na Internet as pessoas têm o controle da situação e não estão dispostas a ler anúncios ou qualquer forma de propaganda ou de publicidade; por se tratar de mídia interativa, o usuário tem o poder de rejeitá-la. Isso não implica que não haverá propaganda na Internet, mas que ela não será uma mídia tão forte quanto a televisão.

A propaganda na internet, atualmente, é algo normal, as pessoas já não acham um absurdo, mas isso não 
quer dizer que todas gostam. Há empresas que utilizam, além da publicidade virtual, a propaganda televisiva, para que o consumidor saiba da existência da empresa, instigando as pessoas a visitarem o site, quer por curiosidade, quer para efetuar a compra.

Conforme Castro (2000 apud TOLEDO; CAIGAWA; ROCHA, 2006, p. 129),

[...] a Internet é a única mídia que permite combinar o poder da comunicação de massa de emitir uma mensagem e alcançar grande audiência com as possibilidades de interação e feedback. Ainda, segundo o mesmo autor, a Internet oferece meios de anunciar produtos, vendê-los, responder a solicitações dos consumidores e finalmente fidelizá-los; os pontos fortes dessa nova mídia são: a interatividade, flexibilidade, monitoramento e a segmentação.

Contudo, deve haver uma maior conscientização dessas empresas, ao fazerem o uso da internet para promover seu produto; as propagandas devem ser claras, para que todos os públicos as entendam. Além disso, têm de chamar a atenção do internauta para que este pare para olhar e ler a mensagem; passar segurança na hora de efetuar a venda; ter informações concisas e interessante e, principalmente, fazer o uso correto do email, pois é esta a ferramenta mais utilizada pelas empresas do comércio eletrônico e por seus clientes.

Churchill e Peter (2000 apud TOLEDO; CAIGAWA; ROCHA, 2006, p. 13),

[...] descrevem algumas vantagens da Internet sobre outras mídias, como por exemplo: as mensagens podem ser personalizadas; não há custo adicional para alcançar o público mundial distribuído; sendo que nesta podem ser incluídas palavras, figuras, sons e vídeos. Por outro lado, os autores admitem haver alguns limitadores dessa mídia, como estes: nem todos os internautas entendem a mensagem utilizada no anúncio em um web site; a qualidade das imagens varia em função do equipamento e da banda disponível; a audiência restringe-se aos usuários da internet que têm algum interesse na empresa. No produto ou serviço; na questão da segurança.

Portanto, o comércio eletrônico é grande facilitador dos negócios, tornando o processo de venda fácil, seguro, rápido e transparente, reduzindo os custos das empresas que atuam nesse segmento e estimulando a competitividade.

Porém, dentre todas essas vantagens, a falta de contato com o produto, a impessoalidade e a falta de confiabilidade do cliente para com a empresa ainda geram certo desconforto na hora de efetuar a compra, fazendo com que o cliente, muitas vezes, desista de comprar.

\section{RESULTADO DA PESQUISA}

Os questionários foram aplicados a 168 pessoas, sendo estas 112 mulheres e 56 homens, cujas funções vão desde professores e funcionários, a alunos na Faculdade de Tecnologia Senac, de São Miguel do Oeste.

A faixa etária dos entrevistados é de 16 a 18 anos (31,54\%); 19 a 30 anos (58,33\%); 31 a 41 anos (7,14\%) e acima de 42 anos (2,97\%).

A escolaridade dos entrevistados é de 1,78\% fundamental incompleto, 1,78\% fundamental completo, $15,47 \%$ médio incompleto, $23,80 \%$ médio completo, $36,90 \% 3$ o grau incompleto e 17,26\% 3o grau completo. Isso se deve à faculdade trabalhar além de um curso tecnólogo, com cursos livres e técnicos.

Quando questionados os entrevistados sobre o costume de fazer compras pela internet, a grande maioria comentou que não a realiza (Gráfico 1).

Gráfico 1 - Você costuma fazer compras pela internet?

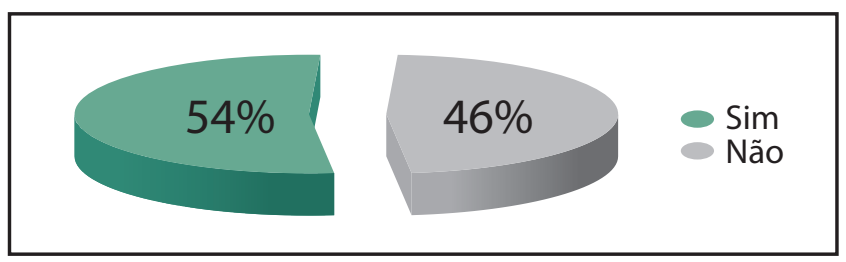

Fonte: As autoras (2011) 
Bagozzi e Lee (1999 apud LIMEIRA, 2007) estudaram o processo de resistência e adoção de inovações, como o comércio eletrônico. De acordo com eles, a resistência a inovações é entendida como um caso específico da resistência genérica à mudança. A resistência do consumidor pode ser ativa ou passiva, provocada por fatores como: princípios religiosos, princípios de conduta adotados pelo grupo de referência, valores familiares, conceitos de identidade, hábitos, atitudes, aversão ao risco, entre outras.

Toda evolução tecnológica requer aceitação, no caso do comércio eletrônico, precisa-se da aceitação dos consumidores, para que utilizem esse meio para suas compras. Todavia, a resistência de alguns ocorre em virtude da cultura ou referências negativas de quem já utilizou o meio.

Dentre os consumidores que já efetuaram compras, é elevado o percentual dos que fazem esporadicamente, de acordo com o Gráfico 2.

Gráfico 2 - Com que frequência faz compras pela internet?

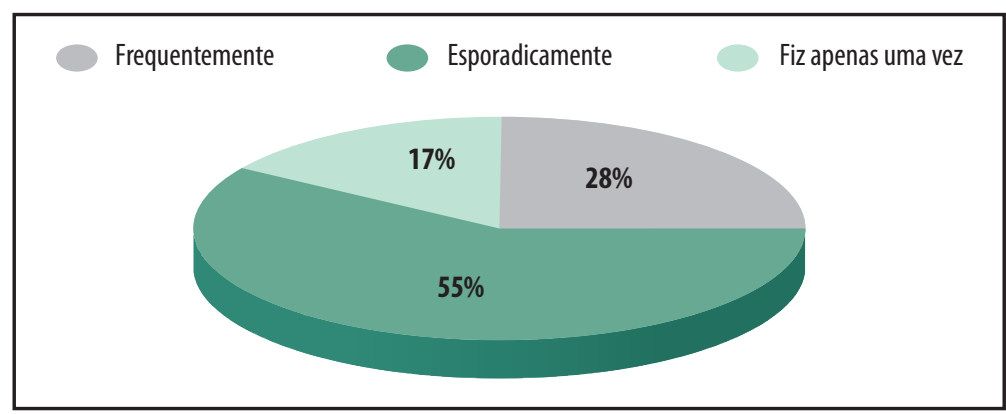

Fonte: As autoras (2011)

De acordo com Limeira (2007), a experimentação é quando o consumidor avalia o produto e o local da compra. No caso do comércio eletrônico, o consumidor compra uma pequena quantidade ou um produto e sem nenhum compromisso de repetição.

Ainda segundo Limeira (2007), se a primeira experiência for satisfatória, a tendência é repetir a compra, podendo fazê-la frequente ou casualmente. Entretanto, se fizer apenas uma vez, é porque não houve um resultado satisfatório a quem adquiriu algum produto ou serviço no comércio eletrônico.

Percebemos que, com a crescente evolução da tecnologia, o comércio eletrônico começa a alavancar as vendas, é um meio que cresce a cada dia por sua disponibilidade ao consumidor. Já os itens comprados na internet pelos entrevistados são diversos, conforme demonstra o Gráfico 3.

Gráfico 3 - 0 que você costuma comprar?

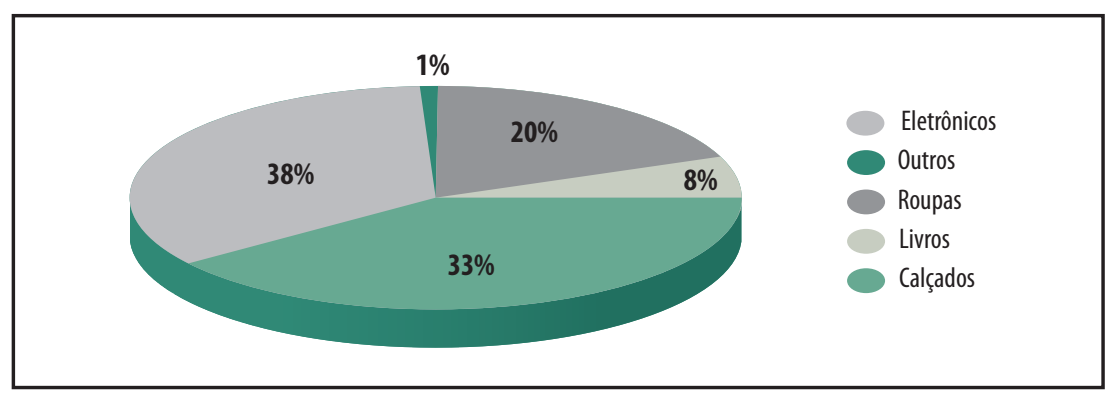

Fonte: As autoras (2011)

Limeira (2007) salienta que os itens mais comprados pela internet mundialmente são: livros, vídeos/DVD/jogos, passagens/reservas aéreas e roupas/acessórios/calçados. Na América Latina, os livros e os equipamentos eletrônicos são os favoritos nas compras on-line.

Observamos que os alunos da Faculdade de Tecnologia Senac, de São Miguel do Oeste, não têm o hábito de comprar livros e, por ter um perfil de alunos mais jovens, a preferência de compra conforme demonstrou a pesquisa foi por eletrônicos e calçados. 
A pesquisa demonstrou que os valores gastos nas compras pelos usuários pesquisados variam de até $\mathrm{R} \$$ 50,00 (4\%), de $\mathrm{R} \$ 50,00$ a $\mathrm{R} \$ 150,00$ (34\%), de $\mathrm{R} \$ 151,00$ a $\mathrm{R} \$ 200,00$ (31\%) e os outros 31\% gastam mais de $\mathrm{R} \$ 201,00$.

A renda mensal dos entrevistados é de $\mathrm{R} \$ 501,00$ a $\mathrm{R} \$ 1.000,00$ (52\%), e o valor gasto em média nas suas compras é de $\mathrm{R} \$ 50,00$ a $\mathrm{R} \$ 150,00$. Constatamos, em conversas informais, que a grande maioria dos entrevistados ainda mora com os pais, o que facilita as compras, não tendo assim tantas contas para pagar como quando se mora sozinho, fazendo com que eles consumam produtos de desejo.

Verificamos na pesquisa de campo que há consumidores que pesquisam sites de compra, mas nem sempre a efetuam, conforme mostra o Gráfico 4.

Gráfico 4 - Quando você pesquisa sites de compras?

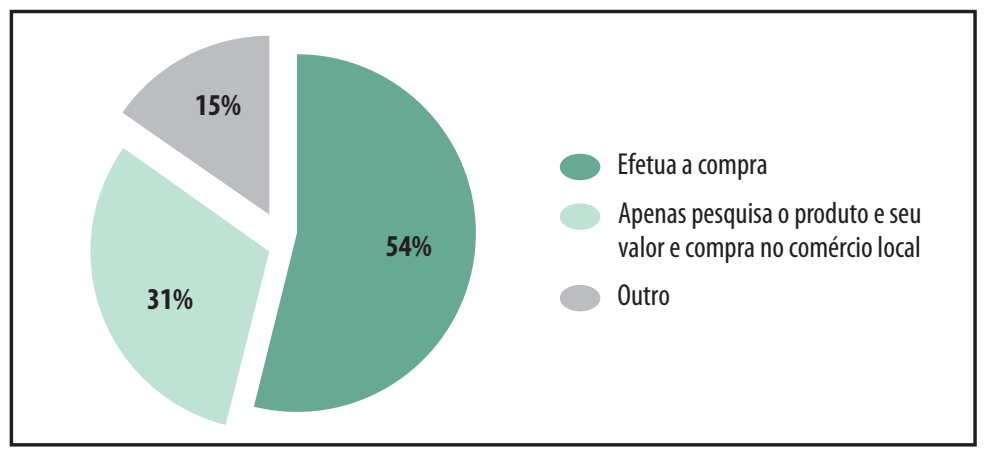

Fonte: As autoras (2011)

Conforme Limeira (2007), a efetuação de uma compra, quando realizada imediatamente, ao pesquisar os sites de compra, pode ser justificada pelo perfil dos consumidores, o que acontece com os jovens, em realizar compras por impulso.

Quanto à pesquisa de campo, percebemos que o perfil dos consumidores é, em sua maioria, de jovens, o que talvez explique a efetuação da compra (54\%).

Quando questionamos os entrevistados que já compram pela internet se houve algum problema referente ao produto, entrega, mau uso das informações pessoais, etc., 91\% deles comentaram que nunca tiveram problemas, enquanto $9 \%$ dos pesquisados tiveram. Porém, dos $9 \%$ que tiveram algum tipo de problema, 57\% conseguiram solucioná-lo rapidamente, conforme verificamos no Gráfico 5.

Gráfico 5 - Se você teve algum problema, você conseguiu solucioná-lo rapidamente?

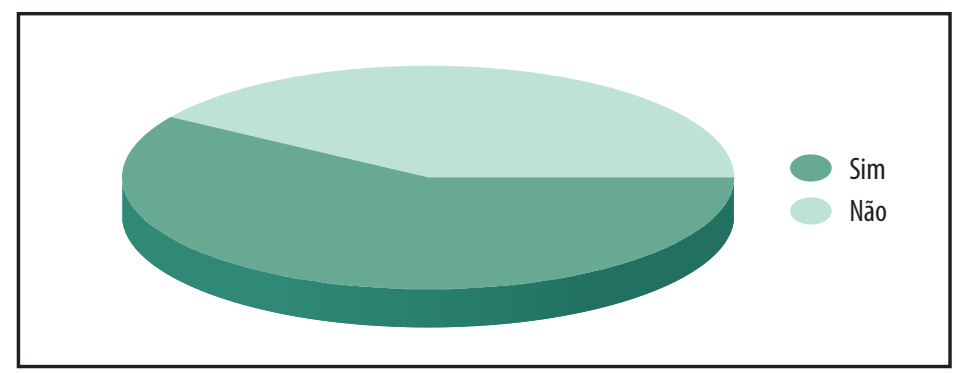

Fonte: As autoras (2011)

No caso, os maiores problemas estão relacionados ao mau uso das informações pessoais financeiras por terceiros, isso também pode fazer com que muitos desistam de efetuar compras pela internet. A maioria prefere concluir a transação por contato telefônico ou semelhante, pois teme que informações do cartão de crédito possam ser interceptadas.

Os fatores psicológicos inerentes a cada pessoa, como personalidade, atitudes, motivação, percepção e aprendizado, bem como suas experiências anteriores afetam todo o processo de decisão de compra (LIMEIRA, 
2007).

Na pesquisa, 78\% dos entrevistados afirmam que o e-mail é a principal ferramenta de comunicação da empresa e o consumidor. Limeira (2007) salienta que o e-mail é um dos meios mais importantes de comunicação empresarial atualmente.

0 mesmo autor acrescenta que enviar e receber e-mails com certa frequência pode ser decisivo para obter informações e feedback dos clientes, criar relacionamento duradouro e desenvolver um negócio.

Os entrevistados foram questionados se o uso do comércio eletrônico modifica a relação entre consumidor e empresa, $83 \%$ disseram que sim e $17 \%$ que não.

Uma das causas de modificar a relação entre consumidor e empresa é a impessoalidade e a falta de contato com o vendedor, pois o e-mail, conforme diagnosticado na pesquisa e sugerido por Limeira (2007), é o canal de contato mais utilizado entre empresa e cliente.

De acordo com a opinião geral dos consumidores pesquisados, a principal vantagem do comércio eletrônico pode ser observada no Gráfico 6.

Gráfico 6 - Vantagens do comércio eletrônico

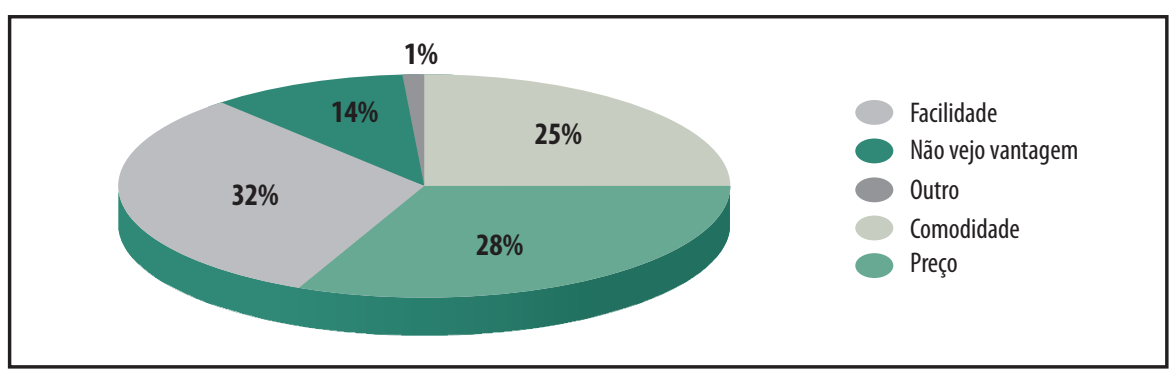

Fonte: As autoras (2011)

Conforme Sterne (1995 apud FERREIRA; SERRA, 2004), o comércio eletrônico tem uma facilidade para o consumidor, também pela concorrência, afinal se está a um clique com o mouse para conhecer o preço, produto e serviço dos concorrentes, assim proporcionando uma melhor vantagem ao cliente.

Conforme Clarke e Flaherty (2005 apud GARCIA, 2007), as principais vantagens do comércio eletrônico são a disponibilidade de compras 24 horas por dia, durante todos os dias da semana; seleção de produtos maiores; preços mais baixos; rápida entrega (dependendo do local); acesso ao serviço de relacionamento com o cliente; tratamento personalizado; oportunidade para comunicações bilaterais; conveniência de comprar on-line; privacidade; não há pressão da equipe de vendas; facilidade de busca e comparação; baixos custos de troca; benefícios de filtros colaborativos, como grupo de usuários.

Percebemos, portanto, que as vantagens citadas pelos entrevistados não diferem das comentadas pelos autores estudados.

Quando se trata de abordar as desvantagens do comércio eletrônico, os itens relacionados à falta de contato com o produto e à falta de segurança têm posição de destaque, como apresentado no Gráfico 7.

Gráfico 7 - Desvantagens do comércio eletrônico

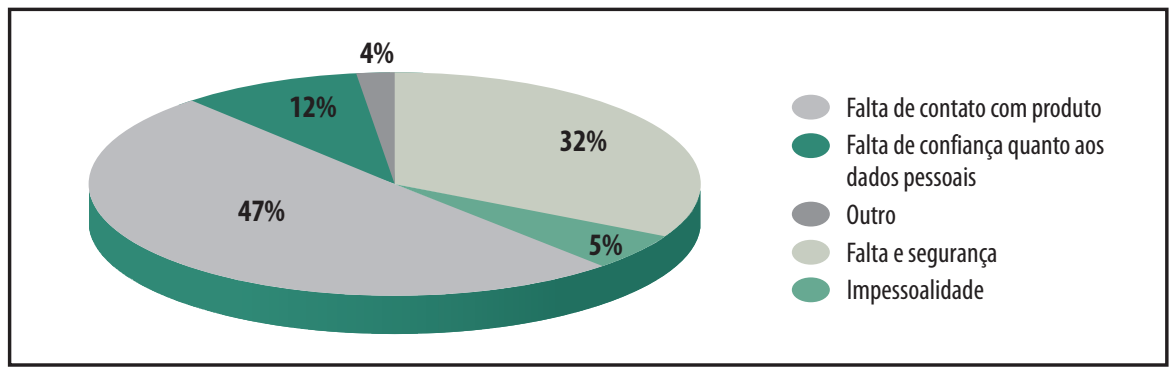

Fonte: As autoras (2011)

Limeira (2007) afirma que as maiores resistências à realização de compras na internet, no mundo, referem- 
se ao mau uso de informações financeiras pessoais, como as de cartão de crédito e o mau uso por terceiros de tais informações.

De acordo com Miyazaki e Fernandez (2000 apud KOVACS; FARIAS, 2004), diversas empresas não têm respeitado a privacidade do consumidor. Ao navegar pelo site de uma empresa, o usuário pode ser monitorado por meio de cookies, que é a habilidade de identificar informações de visitas às páginas da internet. Em grande parte das vezes, isso ocorre sem o conhecimento do internauta. As informações obtidas são combinadas com os dados pessoais fornecidos previamente pelo usuário, permitindo uma análise do comportamento de busca de informações do consumidor.

Catalani et al (2007) ressaltam que o sucesso do comércio eletrônico depende do uso correto de tecnologia de segurança. Para lidar com as situações de segurança quanto aos dados pessoais e financeiros dos clientes, já existem sistemas de segurança extremamente eficazes. Esses mecanismos implementam táticas e técnicas que vão desde a segurança física dos computadores, até a forma como os dados trafegam pelas redes. Em algumas situações, a atividade comercial pela internet é tão segura quanto a realizada num banco, pois muitas das rotinas e programas utilizados por estes também são utilizados pelo comércio eletrônico.

Segundo os mesmos autores, o cliente on-line tem de se sentir especialmente seguro, antes de fazer suas transações, tendo certeza de que seus dados serão mantidos seguros e sigilosos o tempo todo.

Logo, as pessoas pesquisadas não são diferentes das outras e a segurança no meio on-line é sem dúvida a chave de sucesso para que o consumidor busque o meio eletrônico ou não para efetuar suas compras, bem como uma empresa se consolide no mercado ou saia dele.

\section{CONSIDERAÇÕES FINAIS}

Podemos concluir, com a pesquisa realizada, que há uma grande resistência de algumas pessoas em realizar compras no comércio eletrônico, pois 54\% dos entrevistados não fazem uso deste meio, seja por insegurança, ou para pesquisar preços, entre outros motivos; todavia, dos que fazem, realizam as compras esporadicamente.

Os itens mais adquiridos pelos entrevistados são eletrônicos e calçados. Isso se deve principalmente pelo fato de serem pessoas mais jovens, não tendo o hábito de comprar livros, conforme comentário de alguns autores.

Dos pesquisados que não compram pela internet, estes a veem como uma ferramenta que trouxe muita facilidade para compras; no entanto, a falta de contato com o produto e a falta de segurança, segundo eles, geram uma maior desvantagem do que comprar no comércio local.

Quanto à decisão de compra, ela varia com as necessidades e desejos dos consumidores. Todavia, estão inteiramente ligadas com obstáculos tecnológicos; culturais, como a modificação de hábitos de consumo; organizacionais, pela adaptação das empresas ao novo ambiente; fatores psicológicos, como personalidade, atitudes, motivação, percepção e aprendizado dos consumidores.

A experiência de compra on-line bem-sucedida é, talvez, a melhor estratégia de convencimento e adesão ao comércio eletrônico.

$\mathrm{Na}$ pesquisa de campo, observamos que as pessoas que consomem produtos pela internet veem o e-mail como a principal ferramenta de comunicação entre a empresa e o consumidor (78\%) e 83\% afirmam que o comércio eletrônico modifica a relação entre o consumidor e a empresa.

Para os entrevistados, a falta de contato da empresa para com o cliente gera resistência na hora da compra, pois alguns consumidores prezam por um atendimento pessoal (vendedor-cliente), já que aquele procura conhecer suas necessidades, seus desejos, seus anseios, etc.

Já no comércio eletrônico acontece o autoatendimento, pois o próprio cliente pesquisa o produto de seu desejo, e as informações são aquelas que estão descritas. Caso se queira saber mais sobre o artigo que se pretende adquirir, ou fazer uma negociação, utiliza-se o e-mail, que é a principal ferramenta utilizada no comércio eletrônico.

Quanto a pesquisas futuras, sugerimos investigações que analisem o comércio local, pesquisando como as empresas percebem o comércio eletrônico, se fazem uso deste meio e quais as vantagens e desvantagens que ele traz para o comércio local bem como para o município, pois esta ferramenta de compra faz com que o município fique em desvantagem pelo fato de deixar de arrecadar com impostos quando as compras são efetivadas no comércio local. Ao mesmo tempo, o comércio local deixa de lucrar e gerar novos postos de 
trabalho.

\title{
USES OF ELECTRONIC COMMERCE BY PROFESSORS, EMPLOYEES AND STUDENTS AT SENAC COLLEGE OF TECHNOLOGY OF SÃO MIGUEL DO OESTE
}

\begin{abstract}
The electronic commerce is an internet tool, used to do commercial transactions mainly by business-toconsumer. This survey tried to show how can be made the use of electronic business, its consumer's profile, their communication with the company, the advantages and disadvantages of these purchasing tools. The research methods used were exploratory, for the understanding of the study questioning; descriptive, since it was used, as a research instrument, questionnaires and bibliographic research for the knowledge and improvement of the electronic commerce issue. With this survey, the interest of people in using electronic commerce can be noted, although there is still a lack of trust in order to use this purchasing tool. Even those who do not use electronic commerce, believe that there are advantages, such as lower prices than the local business and also the benefits of purchasing without leaving their own home. As disadvantages, should be mentioned the lack o physical access to the product, as well as the lack of security, because the interviewees believe the credit card number may be misused. It is also noted there is still lot of resistance in using electronic commerce, however, for many, should not be regarded only as a technological development, but as much an advantage of the company that works with such tools as the consumer who is able to access several sites, check the products, have prices quoted and eventually make the purchase.
\end{abstract}

Keywords: Electronic Commerce. Consumer. Security.

\section{REFERÊNCIAS}

CATALANI, Luciane et al. E-commerce. 2. ed. Rio de Janeiro: FGV, 2007.

DINIZ, Eduardo Henrique. Comércio eletrônico: fazendo negócio por meio da internet. Revista de Administração Contemporânea, v. 3, n. 1, p. 71-86, jan./abr. 1999.

FERREIRA, Fernando Colmenero; SERRA, Elisabete Magalhães. Fatores condicionantes da inovatividade no comportamento de compra na internet. Revista de Administração Contemporânea, v. 1, n. 1, p. 63-79, 2004.

GARCIA, Gabriel Martim. Comportamento do consumidor virtual: a influência das características pessoais na intenção de compra. 2007. 53 f. Trabalho de Conclusão de Curso (Bacharel em Administração)-Departamento de Ciências da Administração da Faculdade Federal do Rio Grande do Sul, Porto Alegre, 2007.

KOVACS, Michelle H.; FARIAS, Salomão A. Dimensões de riscos percebidos nas compras pela Internet. Revista de Administração de Empresas (RAE-Eletrônica), v. 3, n. 2, art.15, jul./dez. 2004.

LIMEIRA, Tania M. Vidigal. E-marketing. 2. ed. São Paulo: Saraiva, 2007.

TOLEDO, Luciano Augusto; CAIGAWA, Sidney Maçazzo; ROCHA, Thiago. Reflexões Estratégicas sobre o Composto Promocional de Marketing no Contexto da Internet: um estudo exploratório junto a uma instituição financeira. Revista Administração Contemporânea, v. 10, n. 1, p. 117-138, jan./mar. 2006.

VIEIRA, Valter Afonso. Mensuração da qualidade de serviço no varejo eletrônico e seu impacto sobre as intenções comportamentais. Revista de Administração Contemporânea, v. 50, n. 2, abr./jun. 2010. 